Circular ${ }^{4}$ gives an account of a case exhibiting numerous. foci of invasion, commencing as small papules, followed by blisters, and resulting in ulcerations reaching the diameter of balf-a-crown, the duration of the case being 11 days from commencement to a fatal termination.

The case I have described appears worthy of record from it: apparent rarity, from the absence of any severe initial srmptoms. the fact that the temperature was never raised above normal, and from the extreme rapidity with which so large an area of skin was involved, the whole duration from commencement to the fatal issue being only three and a half days.

Ilerne Bar, Kent.

\section{HOSPITAL CAMP SANITATION IN SOUTH AFRICA.}

BY BURTON A. NICOL, M.R.C.S. ENG., L.R.C.P. LoND., EATF CIVIL SURGEOY ATTACHED TO THE ROYAL ARMY MEDTCAL CORPS, YAIAL FIELD FORCE.

Ix my experience as civil surgeon on the staff of two of the large general hospitals in South Africa I was much imjressed with the large amount of sickness prevalent among the orderlies on the hospital staff. As these men are to some extent trained to recognition of the risks of infection and to methods of cleanliness and disinfection one would not expect a very large incidence of disease among them in spite of their exposure to so many risks. They have also, at least in my experience, availed themselves of the advantages of inoculation against enteric fever in a much greater proportion than the ordinary soldier, so that if this has been a benefit it ought to have helped towards reducing disease in their ranks. I have no figures to quote from, but I know that at Estcourt during the first few months of the work of So. 7 General Hospital the nursing of the sick was hampered greatly by the amount of sickness prevalent among the orderlies. To such an extent was this so that in the first four months about one-third of the orderlies who were originally attached to the hospital staff had passed through the wards; most of them had enteric fever, a smaller number suffering from dysentery or diarrhcea of a dysenteric type. At Newcastle (No. 14 General Hospital) there was also a considerable amount of sickness among the orderlies. At first it was not so marked as at Estcourt, but it should be pointed out that the proportion of fever cases in the wards was much smaller here and the disease apparently was of a milder type. At Estcourt the cases were practically all enteric fever and there was a fairly large proportion of severe cases.

My attention was thus drawn to the general sanitary condition of the camps and to the precautions which were being taken to prevent the spread of contagion from patients to those whose duty it was to look after them and restore them to health. At No. 14 General Hospital at Newcastle printed rules were circulated among wardmasters and orderlies as to their duties with regard to the management of infectious cases, the treatment of excreta, \&c. The following is a summary of the observances laid down for their guidance in these regulations and of the general methods employed. Kaffirs at both hospitals were employed as ground scavengers and kept the camp beautifully clean, picking up every scrap of paper, wood, and other refuse. These men, lowever, would have nothing to do with the handling of excreta, so that this was all dealt with by Indians specially employed for the purpose. It was very fortunate that these men were available, as our men were thus able to devote themselves entirely to their nursing duties. When an orderly had placed the night-stool, chamber-pot, or bed-pan containing an enteric or dysenteric stool outside the ten une of these ward Indians at once picked it up and carried it to the enteric fever enclosure where it was emptied into the excreta buckets. It was then washed out with 1 in 800 corrosive sublimate solution, some izal solution (1 in 20) was placed in it, and the utensil was at once returned to the ward. The excreta buckets were kept covered and when three-fourths full were taken to the incinerator, where the contents were boiled down to dryness, mixed with sawdust, and then burnt. The urine was supposed to be treated in

4 Medical Prass and Circul vr, vol, ii., 1889. the same way, but I am afraid that careless orderlies were frequently in the habit of emptying urinals into slopbuckets, which were in turn emptied into separate sanitary handcarts (large zinc drums on wheels). It thus often escaped thorough disinfection.

The soiled linen was always removed in red handcarts from the wards, being first sprinkled with carbolic solution, 1 in 20 ; it was taken to the enteric fever enclosure, placed in boilers and boiled for 20 minutes, dried, and then taken to the foul linen store to be sent to the wash. All mattresses, pillows, and clothing that would have been destroyed by boiling were disinfected in Thresh's steam disinfector. Excreta and all linen from dysentery wards were treated in exactly the same way as if coming from an enteric fever ward. All bed-pans, night-stools, urinals, and slop-pails belonging to enteric fever wards were marked with the letter " $\mathrm{E}$ " in red paint and kept apart in every possible way from similar utensils in other parts of the hospital. They were always kept outside the wards at one particular corner of the tent or marquee. The Indians employed in this sanitary work were used only for removing excreta, slops, and rubbish from the wards, they were not employed on any ordinary fatigue work, such as carrying water, food, \&c., or cleansing utensils for food or drink. They were on duty at all times, so that at night the removal of stools from the precincts of the wards was carried out as promptly as in the day. The enteric fever enclosure was in charge of a non-commissioned officer and he was responsible for the carrying out of all details in connexion with the work of disinfection. He was assisted in his work by one European and three Indians. The floor of this enclosure was of cement; it was cleaned daily and washed with sublimate solution 1 in 800 . Every ward was supplied with a bottle of carbolic solution, 1 in 20, no special bottle was, however. provided and a brandy or other similar bottle was invariably used. This was dangerous, as the wards were not provided with any receptacle where it might be safely and conveniently kept. Orderlies were instructed after handling patients or infected articles and before meals to wash their hands in carbolic solution, 1 in 20, and to use a nail-brush. This order was almost invariably neglected ; the deficiencies in basins, towels, and water undoubtedly discouraged the careful observance of this rule. Separate dinner tins and hot-water trays were kept for enteric fever wards and were all marked with the letter " $\mathrm{E}$."

It will thus be seen that a fairly comprehensive scheme was arranged for the proper treatment and disposal of refuse and infected material and for the prevention as far as possible of the dissemination of disease. Many other points were neglected, and it is possible that a closer attention to detail would have improved upon the reneral results obtained. No general sanitary officer was appointed to exercise supervision over the details laid down in the scheme. This work was divided among the various civil surgeons and Royal Army Medical Corps subalterns, each one acting in turn as sanitary officer for one week ; the work was certainly not done as thoroughly as would have been the case had it been the duty of one man to superintend closely all the details of sanitary work in the neighbourhood of the camp. The orderlies were very inexperienced in hospital work-the majority of them could not be made to understand the gravity of the risks they were running by carelessness with regard to personal cleanliness. They were being constantly changed from ward to ward, so that before a man had time to benefit by the instructions of the nurse and medical officer he was removed to non-fever wards and another novice supplied in his place. They were frequently put on night duty at the end of what was always a long and heavy day's work. This must have acted disadvantageously on their general health, increasing their risks of infection by lowering their resistance to disease. Orderlies, whose work lay entirely in non-fever wards during the day, or even in the office, would be sent into a fever ward for night duty. The disadvantages of such a proceeding to both orderly and patients are very obvious.

Great attention was paid to apparent cleanliness, to such an extent that hardly a straw or burnt match end could be seen in the neighbourhood of the camp; slop water that had been used for washing enteric fever patients was, however, frequently thrown out over the ground instead of being carried away. I have seen a trained nurse do this, and the orderlies frequently did it. It is a very difficult practice to detect and check. Convalescent patients and orderlies were 
in the habit of micturating on the ground after sunset in portions of the camp when they were likely to be unobserved instead of going to the latrine. The ground was thus fouled in many ways, though apparently clean.

There was a scarcity of ward utensils, drinking-cups, tumblers, \&c., so that these articles were frequently used in common. No proper arrangements were ever made for storing milk, beef-tea, \&c., in the wards. Dishes, forks, knives, spoons, \&c., were often not so thoroughly cleansed as they should have been, as this work was done in the wards or immediately outside, which was objectionable. The milk for fever cases was served out three times a day, a pint at a time. This was placed in each patient's bowl on his bedside table; the bowl thus served the double purpose of a drinking-cup and a basin for storing the milk. The consequence of this was that thirsty patients either helped themselves to a large quantity at a time and then waited without food for many hours until the next pint came, or if at all typhoidal neglected it, and it became the food-supply and a death-trap for all the flies in the ward. Patients convalescent from enteric fever and dysentery often used latrines in common with other patients. Efforts were made to prevent this. The urine from enteric fever patients undoubtedly often escaped the thorough disinfection it should have received.

The greatest defect of all in this camp was certainly a very deficient water-supply. The town of Newcastle had for some years found their water-supply insufficient for their own needs and were considering various schemes for improving the supply. With a large general hospital of 520 beds and a very large number of troops quartered in this district the deficiency became suddenly acute. To make things worse the year 1900 was rather dry and the rains came very late in the season. Pipes were laid on over the hospital camp and connected with the town supply; they were, however, usually empty. Water could sometimes be obtained from the pipes for about an hour early in the morning; later in the day it had almost invariably to be carried from a standard at the railway station, which was situated at a slightly lower level than the hospital. A great deal of water was carted in water-carts drawn by mules or oxen. This was unsatisfactory as the carts were of the wooden barrel on wheels type ; they were difficult to keep sweet and clean. They were at one time discovered to be very foul. The men complained that the tea was unpalatable and alleged that the water gave them diarrhœa. The deficiency was so serious that no one could understand why the site was not condemned at once for hospital uses, for it was quite impossible to keep patients in that condition of cleanliness which everyone agrees is essential in a hospital, especially where there was a large proportion of enteric fever cases. A regulation existed that all patients who were sufficiently well should receive a hot bath before admission to the ward. They could not have even a cold bath; the carrying of such water as was used from the carts to the wards greatly increased the amount of work done by the orderlies, and must have discouraged its free use. Nice wash-houses had been erected for the use of convalescent patients, they were filled with rows of bowls with water laid on for each bowl. I never saw water in them except in the very early morning and sometimes not then.

The quantity of soda-water obtainable was limited by the deficioncy of water in the town, the supply being a purely local one. We could not obtain it for our fever cases in the quantity which we thought necessary, the amounts were again and again cut down. It was noticed that although the hospital conld not get the quantity of aerated water it wanted the hotels in the town were never short. The water used by orderlies and patients for drinking purposes was neither filtered nor boiled, that used in the wards was kept in canvas water-coolers outside the tents, to which the dust readily obtained access, The water-supply at Estcourt, I may say, was very good.

The sites were, I believe, usually well chosen. The hospital at Estcourt was in a particularly good position on the slope of a small hill. It was near the railway, so that a special siding was constructed by which means the hospital trains were run right to the bottom of the camp. At Newcastle, however, we were occupying a site which had been used for some months by one of the stationary hospitals before our arrival; it was on a low piece of ground near the river and was much too close to the town. The consequence was that flies were much more troublesome than at Estcourt; the camp, though near the station, had no siding of its own and its position in other respects was undesirable.
I feel certain that a more careful selection of hospital sites might have been made in certain cases, and with a closer supervision over some of the details of sanitary work would have saved a great deal of the sickness among the hospital staff. In this way both directly and indirectly the efficiency of the hospitals wonld have been increased. The authorities did not seem to recognise the fact that a continued use of one particular site was disadvantageous from the consequent fouling of the ground which was being continually carried on when a large number of enteric fever cases were brought together. The great advantage of a canvas hospital is its mobility; this advantage is lost where one site is persistently used for many months in spite of obvious and very serious defects. Some light is also thrown npon the value of the investigations made by the recent Hospital Commission in their flying tour through South Africa when it is remembered that Newcastle was one of the towns visited by them and witnesses were there examined. No comment, so far as I know, has been made by them upon its water-supply, and the hospital, I believe, still exists upon the same site.

\section{ON THE}

\section{BEHAVIOUR OF OXY-HÆMOGLOBIN, CARBONIC-OXIDE-H EMOGLOBIN, METH EMOGLOBIN, AND CERTAIN \\ OF THEIR DERIVATIVES, IN THE MAGNETIC FIELD,}

WITH A PRELIMINARY NOTE ON THE ELECTROLYSIS OF THE H.WMOGLOBIN COMPOUNDS. ${ }^{2}$

BY ARTHUR GAMGEE, M.D. FiDIN., F.R.S.,

EMERITUS PROFESSOR OF PHYSIOLOGY IN THE OWENS COLLEGE, VICTORIA UNTVERSTTY.

\section{I.-The OBSERvations OF FARAday AND Plücker on THE Diamagnetic Properties of THE BLoOd.}

IN the course of his investigations on magnetism and diamagnetism, read before the Royal Society in the year 1845, Faraday ${ }^{2}$ found that, notwithstanding the iron which its colouring matter contains, the blood is a diamagnetic liquid. "I was much impressed," he remarked, "by the fact that blood was not magnetic, nor any of the specimens tried of red muscular fibre of beef or mutton. This was the more striking because, as will be seen hereafter, iron is always and in almost all states magnetic. But in respect to this point it may be observed that the ordinary mag. netic property of matter and this new property are in their efforts opposed to each other; and that when this property is strong it may overcome a very slight degree of ordinary magnetic force, just as also a certain amount of magnetic property may oppose and effectually hide the presence of this force."3 Faraday further found the blood to behave like all the constituent tissues of animal bodies which he investigated and was led to state that "if a man could be suspended with sufficient delicacy, after the manner of Dufay, and placed in the magnetic field he would point equatorially, for all the substances of which he is formed, including the blood, possess this property."4 De la Rive and Brunner, later, suspending a bound-up frog between the poles of an electro-magnet, observed it to assume an equatorial position; thus realising Faraday's prediction that a complex animal organism must be diamagnetic in accordance with the properties of its constituent tissues and of the water which enters so largely into their composition. Shortly after the publication of Faraday's researches on diamagnetism Professor Plücker ${ }^{6}$ of Bonn, in a well-known paper which

1 A paper read before the Royal Society on June 20th, 1901 2 On New Magnetic Actions and on the Magnetic Condition of all 2
On New Magnetic Actions and on the Mag

3 Experimental Researches in Electricity, vol. iii., 1855, p. 36 3 Experimental Researches in Electricity

para. $285 . \quad$ Ibid., para. 2281.

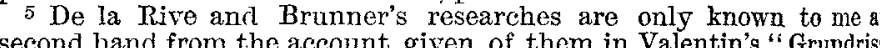
second hand from the account given of thom in Valentin's "Grundriss der Physiologie" (4 Auflage, 1855, p. 507), where an engraving is re produced in which a bound-up frog is shown placed between the poles of the electro-magnet.

6 Experimental Untersuchungen ïber die Wirkung der Magneta auf gasformige und tropfbare Fiissigkeiten. Refer to the heading, "Che das magnetische und diamagnetische Verhalten der tropfbarfliusstgen Kórper," in "Pbggendorff's Aunalen der Physik and Chemie," vol Ixxiii., 1848, para. 49, p. 575 . 